\title{
Students' experiences of learning manual clinical skills through simulation
}

\author{
Eva Johannesson, Charlotte Silén, Joanna Kvist and Håkan Hult
}

\section{Linköping University Post Print}

N.B.: When citing this work, cite the original article.

The original publication is available at www.springerlink.com:

Eva Johannesson, Charlotte Silén, Joanna Kvist and Håkan Hult, Students' experiences of learning manual clinical skills through simulation, 2013, Advances in Health Sciences Education, (8), 1, 99-114.

http://dx.doi.org/10.1007/s10459-012-9358-z

Copyright: Springer Verlag (Germany)

http://www.springerlink.com/?MUD=MP

Postprint available at: Linköping University Electronic Press

http://urn.kb.se/resolve?urn=urn:nbn:se:liu:diva-90153 


\section{Students' experiences of learning manual clinical skills}

\section{through simulation}

Eva Johannesson RPT MSc ${ }^{\mathrm{ac}}$, Charlotte Silén RN PhD ${ }^{\mathrm{b}}$, Joanna Kvist RPT PhD ${ }^{\mathrm{a}}$, Håkan Hult PhD ${ }^{\mathrm{c}}$

a. Division of Physiotherapy, Department of Medical and Health Sciences, Linköping University, SE58183 Linköping, Sweden

b. Centre for Medical Education, Department of Learning, Informatics, Management and Ethics, Karolinska Institutet, SE-171 77 Stockholm, Sweden

c. Centre for Educational Development and Research, Faculty of Health Sciences, Linköping University, SE-581 83 Linköping, Sweden

Corresponding address

Centre for Educational Development and Research, Faculty of Health Sciences, Campus US, Linköping University, SE-581 83 Linköping, Sweden

Telephone $\quad$ +46707335490; +46101038678

E-mail eva.johannesson@liu.se 


\section{ABSTRACT}

Learning manual skills is fundamental in health care education, and motor, sensory and cognitive learning processes are essential aspects of professional development. Simulator training has been shown to enhance factors that facilitate motor and cognitive learning. The present study aimed to investigate the students' experiences and thoughts about their learning in simulation skills training. The study was designed for an educational setting at a clinical skills centre. Ten third year undergraduate nursing students performed urethral catheterisation, using the virtual reality simulator UrecathVision ${ }^{\mathrm{TM}}$ with haptic properties. The students practised in pairs. Each session was videotaped and the video was used to stimulate recall in subsequent interviews. The interviews were analysed using qualitative content analysis. The analysis from observations and interviews resulted in three themes: what the students learn, how the students learn, and the simulator's contribution to the students' learning. Students learned manual skills, how to perform the procedure, and professional behaviour. The students learned by preparing, watching, practising and reflecting. The simulator contributed by providing opportunities to prepare for the skills training, to see anatomical structures, to feel resistance, and to become aware of one's own performance ability. The findings show that the students related the task to earlier experiences, used sensory information, tested themselves and practised techniques in a hands-on fashion, and reflected in and on action. The simulator was seen as a facilitator to learning the manual skills. The study design, with students working in pairs combined with video recording, was found to enhance the opportunities for reflection.

\section{KEYWORDS}

Learning theory; professional development; qualitative content analysis; simulation; skills training; undergraduate nursing education 


\section{INTRODUCTION}

Experienced professionals in health care have manual abilities acquired by skills training, including tacit knowledge (Polanyi 1966). Health care education struggles with how these kinds of skills can be learned in an optimal way.

Over the last twenty years, computerised simulation for skills training in health care education has been evolving at an accelerating rate (Khan et al. 2011). From the focus on technical development, the learning perspective in skill training simulation is now a more focused area (Bradley 2006). Tun and Kneebone (2011) are certain that simulation is here to stay and that its role will increase. They believe that simulation offers particular benefits for mastering procedural skills, as also described in the review by Issenberg et al. (2005) Hatala (2011) states that the question now has changed from 'Is simulation effective?' to 'How is simulation effective?'

Training with a simulator has been shown to enhance factors that facilitate cognitive and motor learning, such as repeated testing, feedback and self-controlled practice (Wolf et al. 2010). This is in line with a study by our research group which identified learning features to be aware of when organising simulation learning. Some of these features are repeated practice, feedback, and active and independent learning (Johannesson et al. 2010). Issenberg et al. $(2005,2008)$ and McGaghie et al. (2010) have discussed similar features to the above and best practices of simulation that educators should know and use. To obtain a deeper understanding of the learning processes, research from fields such as motor learning, neuroscience, and psychology is seen to be particularly valuable (Tun and Kneebone 2011).

Motor learning is defined as learning new movements or modifying movements. This has been described as processes associated with training or experience, leading to relatively permanent changes in the ability to create efficient movement functions. Motor learning emerges from a coherent set of processes related to sensation, cognition and function (Shumway-Cook and Woollacott 2007). Elliott et al. (2011) also express this view; stating that learned and controlled movements are based on an internal structure that contains, for example, sensory, motor and 
cognitive information about an external act as a movement. We perceive through our senses. When learning manual skills we explore objects by touch, using tactile sense with support from visual perception. The simulator user should be able to "feel" a computer-generated object, in a manual task. This technology is known as haptics. Haptic (touch and pressure feedback) technology is a way to have a virtual ability to feel things that do not exist physically (Bergmann Tiest 2010; Scalese et al. 2008).

The main purpose of simulation is to mimic reality in a way that induces a realistic experience (Cioffi et al. 2005; Jeffries 2005). Kahn et al. (2011) emphasize that simulated contexts similar to real life or the workplace help to bridge the gap between classrooms and clinical environments. Moreover, realism creates the basis for meaningful learning (Silén 2003; Murray et al. 2008). A realistic situation to create a context for the learning process is a significant approach in problembased learning, PBL (Silén 2003). Various forms of experiences, such as using different senses and different realistic situations promote curiosity and the desire to learn, which is essential for motivation and meaningful learning (Marton and Booth 1997).

The present study focuses on understanding more about learning clinical skills and on illuminating what simulation might add to students' thoughts and experiences. Educational research studies in medical simulation have been very focused on learning effects and strategies in quantitative terms in order to evaluate, confirm and create evidence for the benefit of simulation in medical education. Bradley (2006) emphasises that research needs to provide convincing evidence of the effectiveness of simulation-based education. McGaghie et al. (2010) suggest that progress in outcome measurement research is needed to advance simulation-based education effectiveness. This study has another approach confirming and creating evidence for the benefit of simulation. It has a qualitative approach; investigating students' perceptions of skills training simulation.

The aim of the present study was to investigate how students perceive that they learn manual clinical skills, i.e. to discover what students are experiencing and what they think about their learning in simulated skills training. 


\section{METHODS}

Qualitative methods in educational research are often used in an attempt to understand a given problem in depth, as it is situated. The aim is to gain deep understanding in order to provide some insight into a given condition and how it arose or could be improved (Denzin and Lincoln 2000).

\section{Design}

To get a better understanding of the phenomenon of learning in computer-simulated skills training, a qualitative research approach was chosen. The study was designed for an educational setting at the clinical skills centre. Ten third year undergraduate nursing students performed urethral catheterisation with the simulator UrecathVision ${ }^{\mathrm{TM}}$. Previously, in semester two, they had practised catheterisation on anatomical models, but learning complex manual skills such as urethral catheterisation only by using low fidelity anatomical models has been shown to be insufficient to allow nursing students to become confident in this skill (Bray et al. 2010). The students practised in pairs. The session was videotaped and the video was used for stimulated recall in the following interviews. The phenomenon of the students' learning was thus studied by observation, interview and stimulated recall in a kind of triangulation method. The analysing method used was qualitative content analysis (Graneheim and Lundman 2004). The inductive processes used helped to build a better understanding of the phenomenon.

Two nursing students, individually, dressed in nursing uniforms, performed urethral catheterisation with the computer simulation programme UrecathVision ${ }^{\mathrm{TM}}$ at the clinical skills training centre Clinicum. Before starting they were given oral information about the simulation process and they answered some background questions in a written form. The simulation programme included questions for reflection both before and after the simulation. The students answered these questions orally. The peer student assisted in the catheterisation procedure and 
acted as a discussion partner. The training was video-recorded to capture comments and events relevant to the study. The camera was on during the whole training session, which lasted for 15 - 20 minutes per student. The students were asked to think aloud and talk to each other. The videos were the basis for the interviews and were used for stimulated recall (Lyle 2003; Polit and Beck 2008). Immediately after the skill training with the simulator the two students were interviewed by one of the authors (EJ). Both students attended, but only one student at a time was interviewed. Besides answering open-ended questions the students could give comments on their performance. Both the interviewer and the interviewee could stop the video using a remote control, and could add comments such as "then I thought, I felt ..." The two students could talk to each other and make comments also in this part. Five pairs of students were interviewed. The reflection sections were not analysed in this study.

\section{Participants}

Ten nursing students participated in the study. They were recruited to the study by e-mail in their sixth and last semester in the bachelor nursing programme at Linköping University in Sweden. When using qualitative methods, the aim is to get as rich descriptions as possible rather than statistically representative ones. The number of students to interview was given in advance. Five pairs of students with ten interviews were considered to be an appropriate number to obtain sufficient data richness from the descriptions. The first ten students who wanted to participate in the study were chosen. Third year students were selected because they had experience from clinical practice, and our assumption was that they had previously had the opportunity to catheterise real patients. According to Denzin and Lincoln (2000), it was a purposeful sampling as the students shared certain characteristics. They were nursing students in the same phase of education and they had different experiences of learning and performing urethral catheterisation. This variety was supposed to ensure enough and rich data.

The students who participated in the study included ten women, three of whom had a different ethnic background. The students' ages were between 21 and 47 years with a mean value of 26.5 
years and a median of 24 years. Two of the students had experience of catheterisation prior to their nursing education. Nine students had catheterised patients once or more, while two had done so more than three times, in clinical practice. Two students had used a simulator earlier in their education. All but one had used simulation devices outside the educational context, for example computer games.

\section{The simulator UrecathVision ${ }^{\mathrm{TM}}$}

UrecathVision $^{\mathrm{TM}}$ is a portable virtual reality task trainer with haptic properties for providing training in the skill of urethral catheterisation (Figure 1). To prepare the students the programme starts with some modules explaining different procedures, using multimedia techniques such as text and images about disinfecting and donning sterile gloves, preparation of the equipment and cleansing the genital area. These preparations are learned using a combination of reading and interactive exercises on the simulator screen. For some of the tasks there are instruction videos. While the user is inserting the catheter, the performance can be followed on the computer screen. Anatomic features are visualised as anatomic cross-section features and updated according to the actions taken. The resistance felt in the catheter is a function of the pathological conditions. The quality of the performance is measured and presented after the catheterisation procedure is completed (www.meleritmedical.com). The assessment form addresses various aspects such as a proper angel of the penis model, sufficient anesthetic at a correct speed and then waits to allow the anesthetic to work. The balloon shall correctly be inflated inside the bladder and then the catheter should be inserted with correct pressure. A summary of the performance is displayed on the screen (Jöud et al., 2010). -Insert Figure 1 here

\section{Data collection and analysis}

The interviews were semi-structured with question areas, and with the opportunity to follow up interesting answers with new questions (Kvale 2007). Question areas for the interviews were: Watch your performance and describe what you thought and experienced. In what ways could the simulator 
facilitate your learning of catheter insertion? What are the advantages and weaknesses? How do you evaluate your learning through the senses, such as touch, sight and hearing in this type of skill training? How could the simulator be an aid? The interviews were tape-recorded and transcribed verbatim. The material was analysed using inductive content analysis, with both manifest and latent content taken into account (Granheim and Lundman 2004.) The interviews were read through several times to obtain a sense of the whole. Then the text about the students' experiences and thoughts was extracted in meaning units that were condensed. The condensed meaning units were abstracted and labelled with codes. The codes were compared and sorted into subcategories and categories. All authors were involved in the analysis and agreed after discussions about the categories described.

A theoretical aspect of learning used in the analysis was a model for the experience of learning by Marton and Booth (1997). They suggest that experience of learning is constituted of what you learn and how you learn. What you learn is the content of what the student learns. How you learn, in this model, is divided into how the act of learning is performed, and what refers to the type of capabilities the learner is trying to develop and master, i.e. the student's intention when learning.

Credibility is a concept that is used in qualitative studies and replaces the concept of validity (Graneheim and Lundman 2004; Meyrick 2006). To ensure credibility in this study, data was collected both from what happened during the simulation, using the video record, and also the students' experiences and thoughts about what was happening during their performance in the following interview. In judging how well the categories cover data and how similarities within and differences between categories were made, agreement among the co-authors and other co-researchers was sought. Another way to approach this was to show representative quotations from the transcribed text. External validity can be explained by the concept of transferability, which is the ability to transfer research to situations with similar parameters, populations and characteristics (Lincoln and Guba 1986). The research setting for understanding students' learning in simulated skills training has similarities with simulation training in other clinical skills centres and in clinical contexts. 
To appraise qualitative research articles, Côté and Turgeon (2005) described a grid with 12 items. In this study these items have been taken into account regarding current state of knowledge, stated objective, the context of the study, an appropriate method for the aim and how the participants were selected, the process of collecting and analysing data by interviews, ensured credible data, and the presentation of results with a figure and citations.

\section{Ethical considerations}

The students knew that the interviewer was not a nurse, so they could carry out the catheterisation in the knowledge that they were not being assessed. The students were informed of the purpose and anticipated benefits of the study. As the students had been trained in urethral catheterisation with low fidelity models during the first year of their education, they were motivated and considered this simulation as an opportunity to fully understand the extent of their previous knowledge, and their skill level. They were also informed that they could withdraw from the study at any time without giving any explanation. The participants had given informed consent. They had a free choice to consent or decline participation voluntarily. With reference to the chairman of the local research ethics committee, no formal ethical approval was required as this kind of educational research does not fall under the Swedish legislation for research ethics.

\section{RESULTS}

The results are described on the basis of the students' experiences and thoughts about their learning in the specific catheterisation situation. Three categories were identified. Two perspectives appeared in the category about what the students learn - situational and professional perspectives. The other categories describe how the students learned and how the simulator contributed to the catheterisation skill training (Figure 1). 


\section{What the students learn in simulated catheterisation skills training}

\section{What the students learn from a situational perspective}

Two areas were identified in the situational perspective. The students felt that they learned to use their hands in a proper way and to perform the catheterisation procedure step by step.

\section{Using their hands properly, manual skills}

The students learned manual skills. In using their hands they developed the ability to modify touch and pressure according to earlier experiences and different kinds of feedback.

The students practised manual skills by holding, pressuring and getting into contact with the material. They were able to feel resistance by different degrees of pressure and they were trained to use one hand for different purposes at the same time.

"One would like to have even more hands to hold and do things simultaneously, but that is something you learn. One can hold three things with one hand if you use your fingers in the right way" (9)

By feeling different kinds of resistance the students learned to modify touch and pressure. They made reflections based on previous experiences, both from clinical practice and from earlier educational skill training.

"It becomes very, very resistant, so you have to press pretty hard" (6)

Some of the students tried to use a tweezers when placing the catheter, but they found that it was difficult to feel the resistance when using this instrument. Using the fingers was experienced as giving better tactile feedback.

"I don't feel how hard I press with the tweezers" (8) 
The students discussed how to hold the catheter or the tweezers during the catheterisation. They verbalised their thoughts about what they were doing.

"You hold it like this then you insert the catheter with the tweezers" (6)

"I hold the catheter so that it cannot slip away" (9)

The students experienced that this kind of learning in simulation training mostly focuses on techniques. They were used to unwrapping sterile equipment and donning gloves. The students used different manual techniques in giving injections. Mostly they pressed with the thumb, but some students pressed with the index finger or the palm of the hand.

"I view this exercise as mostly technical, to practise dexterity with syringes" (1)

\section{Performing the catheterisation procedure}

The students thought it was more important to be trained in procedural and technical skills than to focus on the patient. Their attention was mostly on how to do it, but it happened that some students were well aware of the importance of patient communication.

"Only when I feel confident about my technical skills can I develop communication. When you feel confident you can go and see patients in real life" (1)

"I thought that it was excellent that you had contact with the patient all the time" (3)

"I focused only on how to do it, not on the patient" (5)

The video recording of the catheterisation procedure showed that there was a difference in experiences of catheterisation among the students. Some students were more experienced; they used a structured procedure and they performed and described one thing at a time. Other students gradually remembered the things to do, but they could be in the wrong order. The procedure was not fixed in their mind and they were not confident in the situation. The more experienced students 
managed to do several things at the same time with their fingers. They got a good hold, inserted the catheter calmly and smoothly, were careful with the basin, placed the drainage bag, inflated the balloon, turned out the syringe, laid down the penis, wiped off and took off their gloves before continuing with the next step. They did not become distracted. Some of them also talked with the 'patient'. They had practised this earlier and it had become embodied knowledge. They felt confident in the situation.

"To carry out all the steps, that is what you feel you need to practise the most" (5)

Feedback from the peer student was appreciated.

"I think it is very good to get feedback on what I have done wrong....it was good that you noticed what I had missed" (3)

\section{What the students learn from a professional perspective}

From the professional perspective, the students' behaviour was characteristic of nurses. In watching the video-recording, the students saw how they moved and how they managed disinfection of equipment. In that way the students could see that they were using their previous skill knowledge.

\section{Behaving like a professional nurse, professional development}

The students had experience from clinical practice and they had learned to behave professionally in their motions. The nursing clothes obliged them to move in a certain way and they found that this affected their feeling of seriousness.

"I feel this rather heavy material (of my clothes) and all pockets and it is rather wide here, so you walk against things in a certain way" (1)

"When I wear the clothes, I start to think that I am a nurse and I am going to do this, otherwise it might seem less serious" (2) 
When the students had washed and disinfected their hands the video observation showed that they were very conscious about keeping their hands sterile. All students disinfected their hands very carefully. They were also very careful in managing disinfected equipment such as cloths and basins. They felt that they should not contaminate disinfected equipment. One student strongly reacted when she had to put the simulation catheter on a bench that had not been disinfected.

"I am standing with my hands together so that I do not touch anything else" (4)

"I must disinfect my hands after inserting the catheter; it is very physical. I feel on my hands that I have touched something unclean, my hands must be cleaned before the next patient" (5)

"I cannot touch the bedclothes with the gloves. The sterile part of the canvas must not touch the bedding" (5)

One discussion was about the words the students used in the patient contact. They thought that the patient could feel safer if the nurse behaved in a professional way and named the equipment in a proper way.

"You seem more professional if you know what everything is called and can say it clearly (3)"

When the students evaluated their previous knowledge they became aware of how many different views teachers and clinical supervisors had about how to perform the catheterisation.

"We have previously noticed that there is a great difference between teachers in skills training" (5)

"It is interesting how different perceptions can be. Teachers have different methods, and particularly in clinical practice supervisors do things in very different ways" (6)

"Many teachers have made the skill training such a big deal you believe it is scary and difficult" 


\section{How the students learn catheterisation skills through simulation}

How students learn catheterisation was characterised by preparing, watching, practising and reflecting.

\section{By preparing}

The students were able to prepare themselves by watching instruction videos and images in the simulation programme. They found that the images of patients' faces in different scenarios gave the feeling of a real situation. One video showed how to wash the patient, and this feature was appreciated. They could relate this information to previous knowledge acquired in semester two. Now they felt that they understood how to wash.

"It provides an image of a real patient" (2)

"I can imagine that the patient becomes more anxious if you are not well prepared" (7)

"In semester two I did not understand how to wash properly. It is not obvious" (8)

\section{By watching}

The students found that it was important to see what they were doing. The cross-section image on the screen helped the students learn the catheterisation procedure.

"You have to take it really easy and watch to make sure that it is actually inserted" (10)

The students carried out the catheterisation in pairs and could watch each other's performance. They found that they could learn from each other.

"Did you feel that watching me do it wrong was sufficient for you to do it right the next time?" (1)

\section{By practising}


Two of the students said that they wanted to do the catheterisation on their own without preparation. They thought that the simulation gave the opportunity to repeat, test and practise many times and that it allowed them to make mistakes in a safe environment.

"I still feel that I learn more by doing it myself although I see and maybe understand that it was a bit wrong" (1)

"In this situation it is OK to make mistakes" (2)

When the students had the opportunity to repeat the practice they felt more confident. The simulation made them feel that they needed further practice.

"I have of course noticed that there are things I need to practise to feel confident" (4)

"Repetition was great at this point as we have not done it for some time" (5)

"When you have practised many times you don't find it is that difficult. One should practise these things more often" (10)

Practising with the simulator gave the opportunity to test how to perform the catheterisation in different ways without the anxiety of harming anyone, and the students also thought that they could test their previous skills knowledge.

"I can doing things differently on a real patient" (1)

"You learn by doing something wrong too and here it is OK to make mistakes, so it is useful" (1)

"It's fun to try to see if you actually remember" (2)

The students liked to practise with a peer. They found that they thought differently and that they complemented each other.

"It is good to work in pairs. We think in different ways and we complement each other very well" (6) 


\section{By reflecting}

The students thought that the simulated situation gave opportunities for reflection on their own skills.

"I've been thinking about how I perform" (8)

One student felt like a beginner because she had not repeated the catheterisation procedure learned in the skill training in semester two, and could not carry out the steps in the right order. At the same time she felt her dexterity was good.

"I was not up to date and I had not done this a lot, so I felt very much like a beginner .... but anyway, mentally I feel that I am a trained nurse" (1)

The students felt that it was valuable to have someone to reflect with during the procedure.

"It is good for students to work in pairs so you have someone to discuss with. We talk to each other and we can share our thoughts and ask each other" (7)

\section{Contributions of the UrecathVision ${ }^{\mathrm{TM}}$ simulator to the students' learning of catheterisation skills}

The simulator contributed to the students' learning by providing opportunities to prepare for the skills training, to see the related anatomy, to feel resistance, and to become aware of their own performance ability.

The students felt that it might be good to have a simulation environment for practising on their own without a teacher when they had spare time to practise.

\section{Opportunities to prepare for the skills training}

The experience was that instructional videos and images were helpful in the simulation skill training.

"... and there is this demonstration video if you feel that you need a reminder of how to do it" (2) 
"If you are not sure about something you can go back and check these instructions. It is very pedagogical, with both text and images" (8)

The patient scenarios served as background information. The students could imagine real persons with different kinds of problems. This authentic information was helpful and the students found it useful for preparing themselves.

"We received some background information about his problem. Then it felt more like a real person" (7)

"I thought that it was very good to be given a scenario. There are probably different scenarios depending on which man you choose" (8)

\section{Opportunities to see the anatomy}

In the catheterisation procedure the students looked at the images on the screen, and these were seen as facilitating the development of manual skills. Seeing the anatomy was an appreciated feature of the simulation programme. They could see what happened and follow the consequences of their actions. This experience helped the students to gain a deeper understanding of the anatomy involved in the catheterisation procedure.

"It was good that I also saw the anatomy at the same time and saw the consequences of what I did" (1)

"You could see the anatomy, what it looks like inside, and where you are" (2)

"According to these anatomical images it works in the opposite direction as there will be two bends instead (5)"

"It was fun to see because now we could actually see where the sphincters were. You can see the anatomy very well" (6) 


\section{Opportunities to feel resistance}

The students appreciated the tactile feedback when they injected anaesthetic fluid and inserted the catheter, and they could understand that the feedback varied according to which patient case they chose.

"I tried to pull carefully because I thought that it would come out then, but actually it did not. There was resistance, so it was very good... felt like an advanced technique" (1)

"What happens if I bend to this angle, why is there resistance now? If I bend it upwards, it is a lot smoother" (1)

"One felt that there was some resistance. It takes a while before it comes down and you have to press hard. But there is resistance from the start in reality too" (7)

\section{Opportunities to become aware of one's own performance ability}

The simulator was equipped with an assessment module to measure the quality of performance continuously. The students found this motivated them to find out the results of their catheterisation performance ability.

"It was good that we received assessment points" (2)

"It was good to see what they thought that I could do, and I got a kind of grade. Now I can see clearly what was right" (3)

"I got rather high scores and then I felt pretty good; it was a confirmation of what I can do" (7)

\section{DISCUSSION}


This study contributes to the existing research in strengthening the value of using simulation techniques in health care education. The results are in consonance with previous reports, e.g. Issenberg et al. (2005) and McGaghie et al. (2010) and add their validity from the learners' perspective. Our result indicates that tactile and visual senses provide much information in the learning process. How we learn manual skills through our senses is an area for urgent further investigation. An authentic context influenced how the students learned. A realistic context benefits seriousness in the professional behaviour. Working in pairs was described by the students as valuable for reflection and different kinds of feedback. Peer learning is used in clinical placements, but it has not previously been discussed in relation to simulation skills training (Bjerrum, 2011).

The results of this study indicates that learning through visualised anatomic features for simulation might provide a new way of learning anatomy as a complement to ordinary education. Anatomy images were experienced as valuable contributions to the students' learning in the simulated catheterisation. The experience helped the students to a deeper understanding of the anatomy involved in the catheterisation process.

The students felt that their focus was on carrying out the procedure in the correct manner. They experienced the exercise as mainly technical and thought that they needed to practise it first. Many repetitive motor tasks can become automatic with enough practice, thereby leaving spare attention capacity for performing other activities (Stefanidis et al. 2007). The video recording showed that some basic skills and behaviours were embodied and some of the students were confident in the catheterisation action to a certain extent. Repeated practice with the simulator and feedback from the video recording and a peer student help in the development of confidence that is fundamental in developing manual skills in all stages of education. A consequence of confidence in an action is that we focus less on how to do it than on the intention of the action (Silén 2006).

Students in this study pointed out that the nursing uniform affected their behaviour. They experienced and saw in the video that they behaved like nurses and that they became more serious in the training situation. Besides being dressed like a nurse, a realistic and authentic environment 
was considered to benefit how the students experienced seriousness in the situation. Thus, a simulation represents a clinical situation "as-if" it were real. This study suggests that even in part task simulation training it is worth to make environmental arrangements for situated learning in supporting seriousness and realistic experiences.

Feedback on skills learning is needed in various ways. Sensory, motor and cognitive aspects have to be taken into account (Elliot et al. 2011). In this study the students got feedback from the simulator program, from peer students and by watching themselves on the video. UrecathVision ${ }^{\mathrm{TM}}$ is equipped with visual and tactile feedback systems. During the catheterisation procedure the students watched the image on the screen. They could see and get feedback from what happened inside the body as a consequence of their actions. Haptic properties for tactile feedback allow the students to feel different kinds of resistance when inserting the catheter. Learning how to touch and press is an essential competence in manual skills ability. Performance assessment was found to motivate the students to perform the catheterisation with high scores. The students liked to get feedback and they experienced the assessment as a confirmation of their skill ability. By reflecting, the students became aware of how they used their hands and performed the procedure. Working in pairs made it possible to watch and learn from each other. The students appreciated being able to discuss and reflect with a peer during the procedure while they were in action (Schön 1987). Moreover, training with a peer made them feel safer and not so vulnerable. Weidner and Popp (2007) suggest that peer-assisted learning (PAL) may contribute to a positive learning environment. Limitations of the study might be that the participants were self-selected volunteers in the same phase of study, which may pose the risk that they were too similar. Though they had similar educational experiences their attitudes and performance ability differed. They had different experiences of catheterisation in clinical practice. Now in the late phase of their studies, they could discuss and have a critical attitude to the skills training earlier in their education. Although the number of students was adequate, it was a small sample, but when the phenomenon of the students' learning was studied in several ways as a kind of triangulation with observation, interview 
and stimulated recall, we obtained rich data. Another limitation may be that the students were very much occupied with how the simulator worked. We could have let the students become more familiar with the function of the simulator in advance. The simulator was still a prototype at the time of the study and the students had to cope with that.

In this study the importance of learning manual skills through the senses has become evident. This might become an area for further exploration linked to simulation. The significance of experience, the attainment of automatic skills, embodied knowing, tacit knowledge and experiential learning, are other fields for future research in learning manual clinical skills through computer simulation

\section{Educational implications}

The study design, with students working in pairs combined with video recording, was discovered to enhance the opportunities for reflection in skills training.

By using peer learning for skills acquisition students can be more encouraged to take responsibility for their learning and to develop greater self-awareness throughout the process (Goldsmith et al. 2006). Weidner \& Popp (2007) have found that their students using peer-assisted learning reported less pressure, embarrassment, and anxiety

This study argues that independent simulation skills practised while training with a peer or in a group using a video recorder to get feedback seem to be motivational and meaningful. As situated learning is desirable, clinical skills centres should arrange situations that are as similar as possible to clinical reality. The students in this study, who were dressed in nursing uniforms, felt like real nurses. The results also show that realistic simulation equipment enhances seriousness.

In the safe simulation environment some students liked to test previous knowledge and clinical skills by not using the preparation opportunities. In this new situation they wanted to know if they had enough knowledge and experience to perform the catheterisation, and learn from that. This is a way of building knowledge through experiential learning (Kolb 1984). 


\section{CONCLUSION}

The simulation situation seemed to benefit clinical skills learning, and the findings suggest the following features to be aware of when organizing simulation skills training in health care education:

- Independent learning with and without a teacher, with a peer or in a group

- A realistic authentic environment and clothing to enhance seriousness

- Video recording the performance for reflection and feedback

- Using a realistic simulation device to enhance seriousness

- Peer learning for common reflection and feedback

- Repeated training, necessary for motor learning

- Assessment to provide feedback and to encourage seriousness

The authors' conclusion is that the students learn clinical skills with support from simulation skills training in developing manual skills ability, procedural performance and professional behaviour. They learn through their senses. The simulation tool in itself and the arrangement of the simulation situation may trigger optimal use of senses. The experiences of performing, and conscious reflection on the performance, preferably with peer students, emerge as important in the learning process.

\section{ACKNOWLEDGEMENTS}

We thank the students who participated in this study and Sofia McGarvey for revising the English language in the quotes. This study was supported by the Centre for Educational Development and Research, Faculty of Health Sciences, and the Division of Community Medicine, Medical Education, Department of Medical and Health Sciences, Linköping University, Sweden. 


\section{REFERENCES}

Bergmann Tiest, W. M. Tactial perception of material properties. Vision Research, 50, 2775-2782.

Bjerrum, M., Tewes, M., Pedersen, P. (2011). Nurses' self-reported knowledge about and attitude to nutrition - before and after a training programme. Scandinavian Journal of Caring Sciences, doi: 10.1111/j.1471-6712.2011.00906.x. [Epub ahead of print]

Bradley, P. (2006). The history of simulation in medical education and possible future directions. Medical Education, 40, 254-262.

Bray, L., Flynn, A. \& Sanders, C. (2011). The experiences of children's nursing students: Learning urethral catheterisation. Nurse Education in Practice, 11(3), 168-172.

Cioffi, J., Purcal, N. \& Arundell, F. (2005). A pilot study to investigate the effect of a simulation strategy on the clinical decision making of midwifery students. Journal of Nursing Education, 44(3), 185-191.

Côté, L., Turgeon, J. (2005). Appraising qualitative research articles in medicine and medical education. Medical Teacher, 27(1), 71-75.

Denzin, N.K. \& Lincoln, Y.S. (2000). Handbook of qualitative research. (Second Edition. Thousand Oaks, Sage Publications).

Elliott, D., Grierson, L. E. M., Hayes, S. J. \& Lyons, J. (2011). Action representations in perception, motor control and learning: implications for medical education. Medical Education, 45, 119-131.

Goldsmith, M., Stewart, L.\& Ferguson, L. (2006). Peer learning partnership: An innovative strategy to enhance skill acquisition in nursing students. Nurse Education Today, 26, 123-130.

Graneheim, U.H. \& Lundman, B. (2004). Qualitative content analysis in nursing research: concepts, procedures and measures to achieve trustworthiness. Nurse Education Today, 24, 105-112. 
Hatala, R. (2011). Practice makes perfect... sometimes. Medical Education, 45, 114-116.

Issenberg, S. B., McGaghie, W. C., Petrisa, E. R., Gordon D. L. \& Scalese, R. J. (2005). Features and uses of high-fidelity medical simulations that lead to effective learning: a BEME systematic review. Medical Teacher, 27, 10-28.

Issenberg, S.B., Scalese R.J. (2008). Simulation in Health Care education. Perspectives in Biology and Medicine, 51(1), 31-46.

Jeffries, P.R. (2005). Guest Editorial. Technology trends in nursing education: next steps. Journal of Nursing Education, 44(1), 1-4.

Johannesson, E., Olsson, M., Petersson, G. \& Silén, C. (2010). Learning Features in Computer Simulation Skills Training. Nurse Education in Practice, 10, 268-273.

Jöud, A., Sandholm, A., Alseby, L., Petersson, G. \& Nilsson, G. (2010). Feasibility of a computerized male urethral catheterization simulator. Nurse Education in Practice, 10(2), 70-75.

Khan, K., Pattison, T. \& Sherwood, M. (2011). Simulation in medical education. Medical Teatcher, 33, 1-3.

Kolb, D.A. (1984). Experiential learning: Experience as the Source of Learning and Development. (Englewood Cliffs, NJ: Prentice Hall).

Kvale, S. (2007). Doing interviews. (California: Sage Publications).

Lincoln, Y.S. \& Guba, E.G. (1986). But is it rigorous? Trustworthiness and authenticity in naturalistic evaluation. In D.D. Williams (Ed.), Naturalistic evaluation (pp. 73-84). New Directions for Program Evaluation, 30. San Francisco, CA: Jossey-Bass.)

Lyle, J. (2003). Stimulated recall: a report on its use in naturalistic research. British Educational Research Journal, 29(6), 861-878. 
Marton, F. \& Booth, S. (1997). Learning and awareness. (Mahwah, New Jersey: Lawrence Erlbaum Associates, Inc.).

McGaghie, W. C., Issenberg, S.B. (2010). A critical review of simulation-based research: 2003-2009. Medical Education, 44, 50-63.

Meyrick, J. (2006). What is Good Qualitative Research? A First Step towards a Comprehensive Approach to Judging Rigour/Quality. Journal of Health Psychology, 11(5), 799-808.

Melerit UrecathVision. Product information of the computer simulator UrecathVision. Retrieved May 10, 2011, from http://www.meleritmedical.com .

Murray, C., Grant, M.J., Howarth, M.L. \& Leigh, J. (2008).The use of simulation as a teaching and learning approach to support practice learning. Nurse Education in Practice, 8, 5-8.

Polanyi, M. (1966). The Tacit Dimension. (Gloucester, Mass.: Doubleday \& Company, Inc.).

Polit, D.E. \& Beck, CT. (2008) Nursing Research. Generating and Assessing Evidence for Nursing Practice. (Eighth Edition. Lippincott Williams \& Wilkins: Philadelphia).

Scalese, R.J., Obesco, V.T., Issenberg, S.B. (2008). Simulation technology for skills training and competency assessment in medical education. Journal of General Internal Medicine, 23(Suppl 1), 46-49.

Schön, D. (1987). Educating the Reflective Practitioner. (San Francisco: Jossey Bass).

Shumway-Cook, A. \& Woollacott, M.J. (2007). Motor Control. Translating Research into Clinical Practice. (Third edition. Philadelphia: Lippincott Williams \& Wilkins).

Silén, C. (2003). Responsibility and independence in learning - what is the role of the educators and the framework of the educational programme? (In: C. Rust (Ed.), Improving Student Learning: 
Improving Student Learning - Theory, Research and Practice (pp. 249-262). (Oxford: The Oxford Centre for Staff and Learning Development).

Silén, C. (2006). The tutor's approach in base groups (PBL). Higher Education, 51, 373-385.

Stefanidis, D., Scerbo, M. W., Korndorffer, J. R. \& Scott, D. J. (2007). Redefining simulator proficiency using automaticity theory. The American Journal of Surgery, 193, 502-506.

Tun, J. K. \& Kneebone, R. (2011). Bridging worlds: applying the science of motor learning to clinical education. Medical Education, 45, 111-114.

Weidner, TG. \& Popp, JK. (2007). Peer-assisted learning and orthopaedic evaluation psychomotor skills. Journal of Athletic Training, 42(1), 113-119.

Wolf, G, Shea, C. \& Lewthwaite, R. (2010) Motor skill learning and performance: a review of influential factors. Medical Education, 44, 75-84. 
Legend for Figure 1:

Simulation skills training with UrecathVision

Legend for Figure 2:

What students experienced and how they felt about their learning using simulation in skill training. 


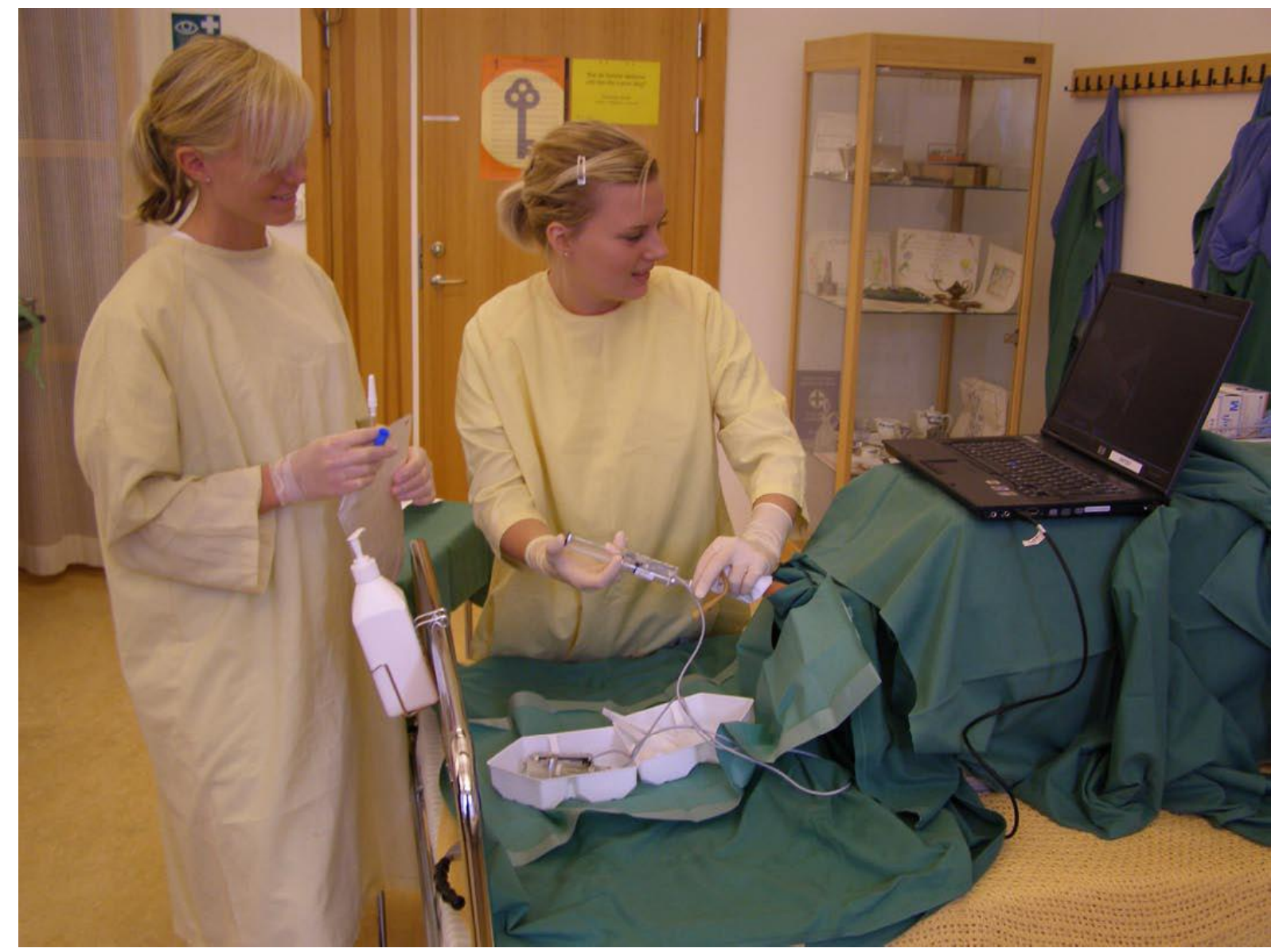

Figure 1.
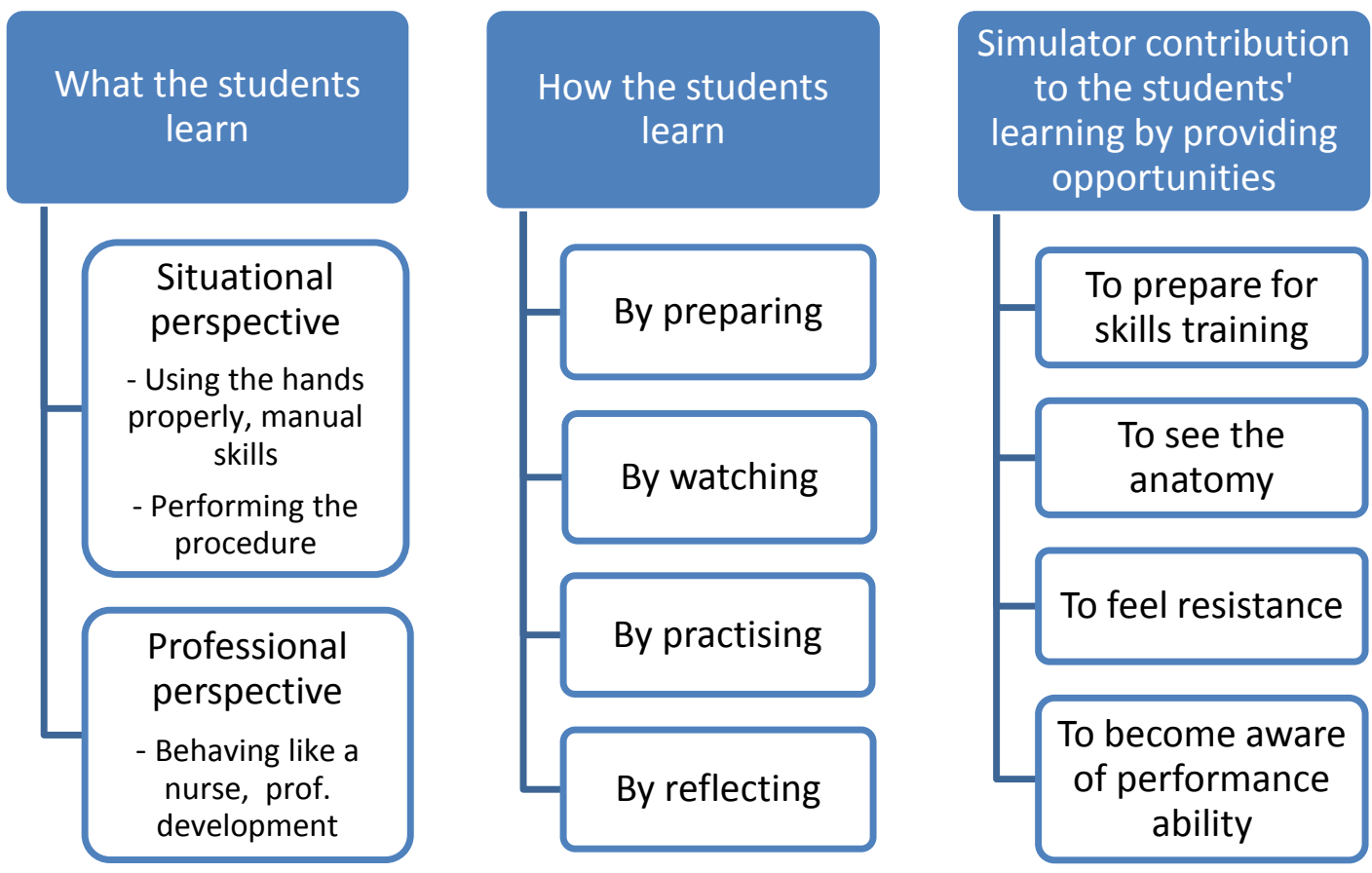

Figure 2. 